\title{
In-situ growing carbon nanotubes on nickel modified glass fiber reinforced epoxy composites for EMI application
}

Yu LIU ${ }^{1,2,3,4}$, Delong HE ${ }^{4}$, Olivier DUBRUNFAUT ${ }^{5}$, Anne ZHANG ${ }^{4}$, Lionel PICHON ${ }^{5 *}$, Jinbo $\mathrm{BAI}^{4 *}$

1 Powder Metallurgy Research Institute, Central South University, 410083 Changsha, PR China

2 State Key Laboratory of Powder Metallurgy, Central South University, Changsha, Hunan 410083, China

3 Hunan Province Key Laboratory of New Specialty Fibers and Composite Material, Central South University, Changsha, Hunan 410083, China

4. Université Paris-Saclay, CentraleSupélec, CNRS, Laboratoire de Mécanique des Sols, Structures et Matériaux (MSSMat), 91190, Gif-sur-Yvette, France

5. Université Paris-Saclay, CentraleSupélec, CNRS, Sorbonne Université, Laboratoire Génie électrique et électronique de Paris (GeePs), 91190, Gif-sur-Yvette, France

* Corresponding author:

Prof. Jinbo Bai, Email: jinbo.bai@,centralesupelec.fr.

Prof. Lionel Pichon, Email: lionel.pichon@centralesupelec.fr

Key words: Glass fiber, Carbon nanotubes, Composites, Nickel coating, EMI shielding effect 


\begin{abstract}
Glass fiber (GF) reinforced polymer composites have attracted increasing attention due to their excellent performance. In this study, GF was coated by a thin layer of nickel, and then grafted carbon nanotubes (CNTs) array by a chemical vapor deposition method (CVD). The CNT contents can be varied by changing the CVD conditions. Three types of fillers, nickel coated GF (GF@Ni), GF with CVD grown CNTs (GF-CNTs) and nickel-coated GF with CVD grown CNTs (GF@Ni-CNTs), were used to prepare the epoxy composites. The electromagnetic interference shielding performances were investigated as a function of CNT contents. The GF@Ni-CNTs reinforced epoxy composites, which had the CNTs mass ratio of $9.2 \mathrm{wt} \%$ to the hybrids, showed the best EMI shielding performance among the composites. Their total EMI shielding effectiveness (SE) was higher than $35 \mathrm{~dB}$ in the range of 1-18 GHz, and above $50 \mathrm{~dB}$ in the $\mathrm{X}$ band. By incorporating the nickel layer on the GF surface, the same EMI performance can be achieved with lower CNTs content. For achieving a SE value of $35 \mathrm{~dB}$ in the X band, it needed GF@Ni-CNTs/epoxy with CNTs mass ratio of 3.8 wt $\%$ to the hybrids, instead of GFCNTs/epoxy composites with CNTs mass ratio of $5.2 \mathrm{wt} \%$ to the hybrids.
\end{abstract}

\title{
1. Introduction
}

Arising from the demand of electronic devices and the protection of human beings from electromagnetic pollution, the electromagnetic interference (EMI) shielding materials with features of lightweight and thin thickness have been intensively studied. To improve the shielding performance, many methods have been developed [1-3]. Usually, using metals, such as nickel, copper and stainless steel, was an effective method [4]. However, the metals have high density, which resulted in a low specific shielding efficiency. Therefore, developing lightweight materials which have high EMI shielding properties on a wide frequency range has attracted enormous attentions [5-7], for example, developing conductive fiber reinforced polymer composites [8-10]. 
Glass fiber (GF), which is much cheaper than CF but has similar mechanical properties, is a kind of widely used composite reinforcements [11]. In order to extend their applications in the EMI field, the electrically insulating GF need to be modified to improve their electrical conductivity [12]. Usually, coating metal or other conductive paints on the surface is an effective method to obtain electrically conductive GF $[13,14]$. To achieve high conductivity, a thick layer needs to be coated on the surface, which increase the cost and gain weight. Increasing the conductivity of the polymer matrix is another method, which can be achieved by incorporating conductive particles in the polymer matrix [15]. Among them, carbon nanotubes (CNTs) are the most promising one, due to their excellent properties [16, 17]. Nevertheless, due to their large surface area and ease of Van der Waals force driven aggregation, CNTs are very difficult to disperse uniformly in the matrix.

Many methods have been utilized to improve the CNT's dispersibility in polymer matrix, by modifying the surface of CNTs and improving the dispersion method. Ultrasonic, mechanical stirring and three-roll milling are the most used dispersion methods $[18,19]$. By prolonging the dispersion time or increasing the stirring speed or ultrasonic power, CNT dispersion can be improved. Also, many modification methods have been reported in the literature in order to improve the dispersibility of CNTs. Most of them were achieved by oxidation of CNTs. However, the oxidation and high shear force during mixing process may destroy the intrinsic properties of CNTs, e.g. the electrical conductivity of CNTs will be decreased largely after oxidation [20]. Growing CNTs on nanoparticles to form hybrids became a promising method to improve the CNT's distribution in the polymers $[21,22]$. In our previous work, a hybrid constructed by CNTs and GF has been fabricated by the chemical vapor deposition (CVD) method. The as-prepared hybrids maintained the intrinsic properties of CNTs. Moreover, the length and the growth density of CNTs can be modulated by modifying the CVD conditions $[23]$. 
In this work, two methods, coating metallic layer and growing CNTs on GF surface, have been combined to produce GF reinforced polymer composites with good EMI performance. In brief, a thin layer of nickel was first coated on the GF surface by a typical solution method, then, insitu growing CNTs on GF@Ni surface was conducted by CVD. Three types of fillers, GF@Ni, GF-CNTs and GF@Ni-CNTs, have been incorporated into epoxy matrix to fabricate composites. Their EMI performance has been investigated in details.

\section{Experiment and characterization}

\subsection{Preparation of GF@Ni}

GF was a S2 grade 6/1 twill tissue, which had an average diameter of $9 \mu \mathrm{m}$ and contained 200 filaments in each yarn. All other reagents were in analytic grade and used directly as received. The nickel layer was coated on the GF surface by a typical method [24]. The details were as follows: the GF was sensitized in the $\mathrm{SnCl}_{2} / \mathrm{HCl}$ solution for $30 \mathrm{~min}$. Then, the sensitized GF was activated in the $\mathrm{PaCl}_{2} / \mathrm{HCl}$ solution for another $30 \mathrm{~min}$. After that, the GF was washed by distilled water for several times. The nickel layer was deposited on the treated GF by immersing it into a plating bath, which was comprised of source metal ions $\left(\mathrm{NiCl}_{2} \cdot 6 \mathrm{H}_{2} \mathrm{O}, 5.94 \mathrm{~g}\right)$, metal chelators $\left(\mathrm{Na}_{3} \mathrm{C}_{6} \mathrm{H}_{5} \mathrm{O}_{7} \cdot 2 \mathrm{H}_{2} \mathrm{O} 2.646 \mathrm{~g}\right)$, reducing agent $\left(\mathrm{NaH}_{2} \mathrm{PO}_{2} \cdot \mathrm{H}_{2} \mathrm{O}\right)$ and $\mathrm{pH}$ stabilizer $\left(\mathrm{NH}_{4} \mathrm{Cl}, 8.344 \mathrm{~g}\right)$. The thickness of the nickel layer could be changed by controlling the deposition time. In this work, the deposition process, lasting $20 \mathrm{~min}$, was carried out in a water bath, whose temperature was set at $45^{\circ} \mathrm{C}$.

\subsection{Growth CNTs on GF tissue}

The growth of CNTs was carried out by CVD method. More details can be found in our previous work [23]. In briefly, the process was conducted for $10-20 \mathrm{~min}$ at $600-650{ }^{\circ} \mathrm{C}$. Two series of samples, with or without nickel layer, were obtained, which were named as GF@Ni-CNTs and GF-CNTs, respectively. 


\subsection{Composite preparation}

The epoxy resin 1080S (Resoltech, France) and the curing agent 1084 (Resoltech, France) with a mass ratio of 3:1 was used as the matrix. The composites were fabricated by a coating-curing method [23]. Four types of composites were fabricated, which were named as Original GF/epoxy, GF@Ni/epoxy, GF-CNTs/epoxy and GF@Ni-CNTs/epoxy, respectively. Then, all the composites were cut into certain sizes for further tests.

\subsection{Characterizations}

The mass fraction of CNTs on the GF and the mass fraction of epoxy in the composites were evaluated by thermogravimetric analysis (TGA, NETZSCH STA 449 F3). The TGA was conducted from room temperature to $900{ }^{\circ} \mathrm{C}$ at an atmosphere of oxygen and nitrogen with a ratio of 4:1. The morphology and microstructure of the samples were characterized by scanning electron microscopy (SEM, LEO 1530 Gemini). X-ray diffraction (XRD, Bruker D2 PHASER with X-Flash 430) was used to characterize the structure of nickel layer. The EMI shielding properties of were evaluated in 1-18 GHz by a network analyzer (Keysight E8364C). Samples with $7 \mathrm{~mm}$ in diameter and less than $1 \mathrm{~mm}$ in thickness were polished and placed in a metallic sample holder, the whole being between two coaxial wave-guides. One coaxial guide was connected to the port 1 , the other was connected to the port 2 of the network analyzer. The calibration planes were in the interfaces sample/coaxial wave-guides. The scattering parameters were obtained to calculate the shielding effectiveness (SE), in which $\mathrm{S}_{11}$ and $\mathrm{S}_{22}$ were the reflection parameters $\left(S_{11}=S_{22}\right), S_{21}$ and $S_{12}$ were the transmission parameters $\left(S_{21}=S_{12}\right)$, respectively. The SE can be calculated by the following equations:

$$
\begin{aligned}
& S E_{R}=-10 \lg \left(1-\left|S_{11}\right|^{2}\right) \\
& S E_{A}=-10 \lg \left(\frac{\left|S_{21}\right|^{2}}{1-\left|S_{11}\right|^{2}}\right)
\end{aligned}
$$




$$
S E_{T}=S E_{R}+S E_{A}+S E_{M}
$$

where $\mathrm{SE}_{\mathrm{T}}$ was the total shielding effectiveness, $\mathrm{SE}_{\mathrm{R}}$ was the reflection part, $\mathrm{SE}_{\mathrm{A}}$ was the absorption part, and $\mathrm{SE}_{\mathrm{M}}$ was the multi-reflection part and can be negligible when $\mathrm{SE}_{\mathrm{T}}$ was larger than $15 \mathrm{~dB}[25]$.

\section{Results and discussion}

\subsection{Preparation of GF@Ni}

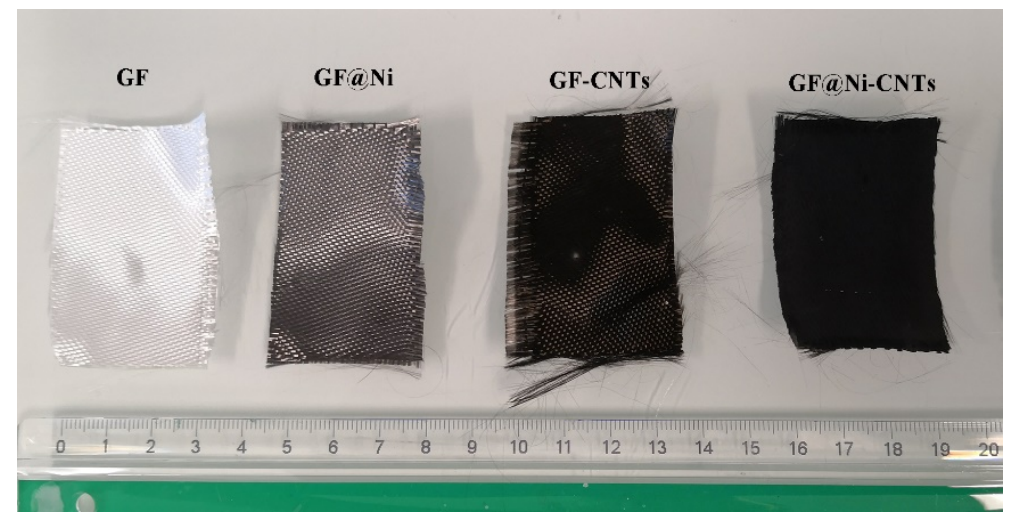

Figure 1 Optical photographs of the GF, GF@Ni, GF-CNTs and GF@Ni-CNTs.

Figure 1 showed the morphology of GF after different surface treatment. After deposited a nickel layer on the tissue, the white tissue turned to gray. The shadows appearing on GF-CNTs were caused by the bending and wrinkles of the fiber tissue. After CNTs grow on the surface of glass fibers, the color generally darkens as the content of CNTs increases. The GF-CNTs shown in the picture was gray, due to the low content of CNTs. When the content of CNTs increased, the tissue color became black, as shown in GF@Ni-CNTs. Figure 2 showed the XRD patterns of the as received GF and the GF@Ni. The XRD pattern of the as-received GF appeared a broad peak at around $24^{\circ}$. After coated by nickel layer, a sharp peak $\left(2 \theta=44.7^{\circ}\right)$ appeared in the XRD pattern, which corresponded to the (111) planes of face-centered cubic nickel [13]. It indicated that the nickel layer was successfully coated on the tissue. 


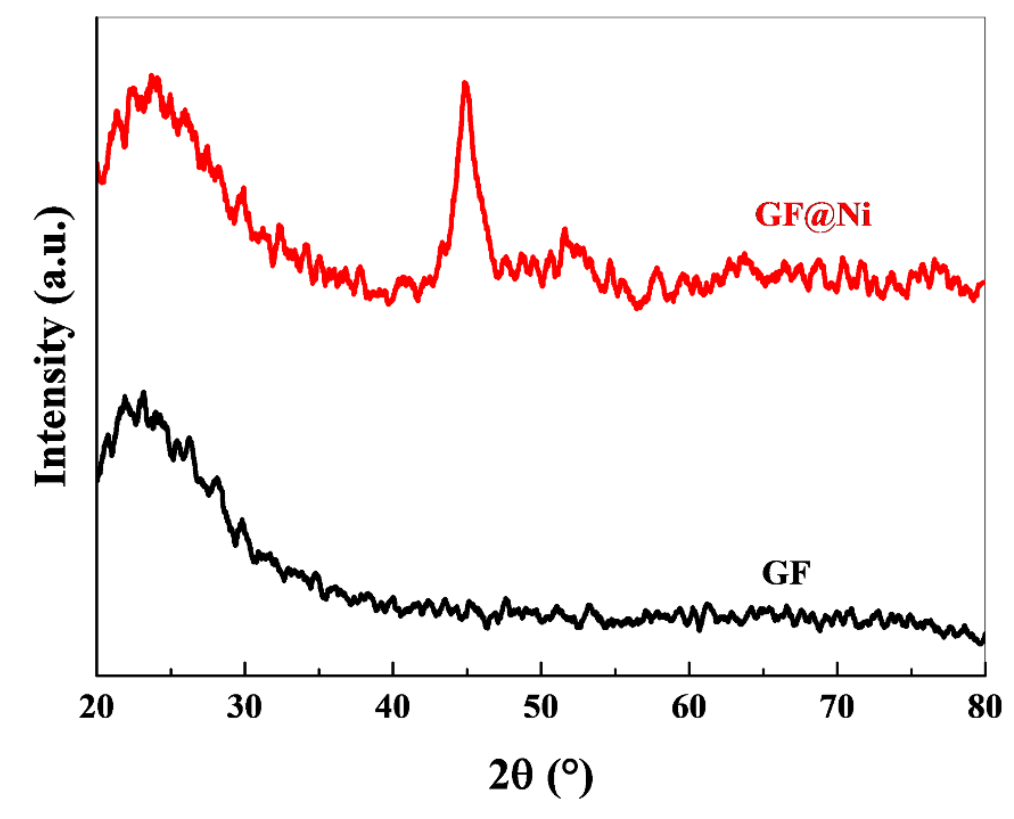

Figure 2 XRD pattern of the as-recieved GF tissue and GF@Ni.
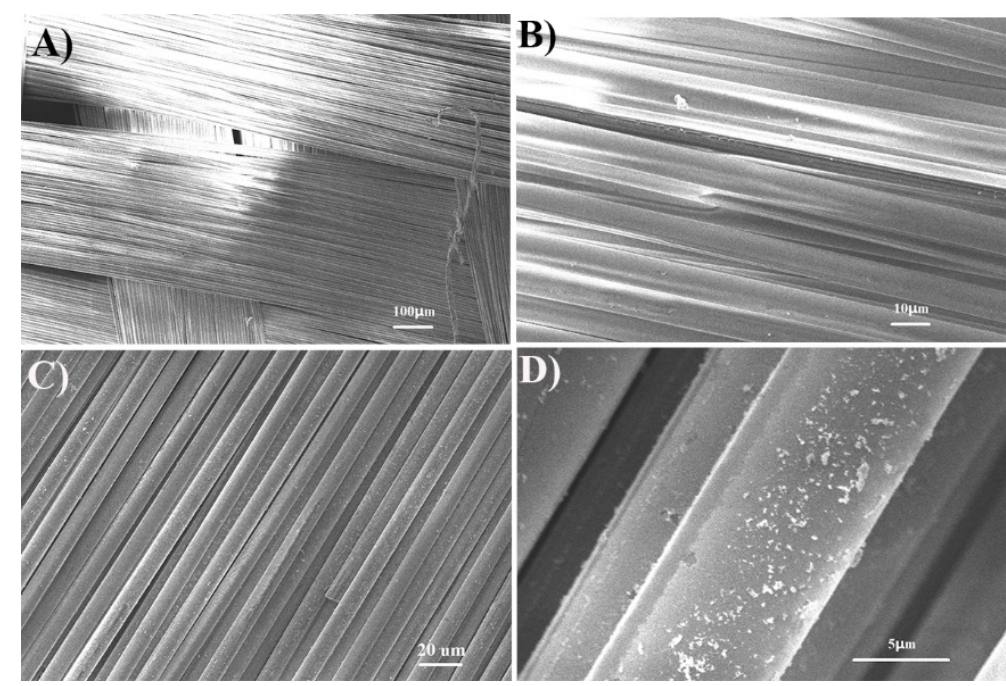

Figure 3 SEM images of (A), (B) as-received GF and (C), (D) GF@Ni.

Figure 3 showed the surface morphology of as-received GF and Ni coated GF (GF@Ni). The GF had an ultra-smooth surface with an average diameter of 9 um, as shown in Figure 3(A) and 3(B). Figure 3(C) showed the GF coated by nickel layer. The coating was found very uniform. The nickel layer can be clearly observed at high magnification, as shown in Figure 3(D). The un-coated region may be caused by the attached adjacent GF. The bright particles appeared on the GF@Ni was the excess nickel particles in the solution attached on the GF@Ni surface. Since the nickel layer was relatively thin, its thickness can be roughly estimated to be 
about 100 nanometers. Comparing to the method mentioned in the ref $[13,26]$, the thickness of nickel layer was much thinner and the nickel particles to form the layer were much smaller in this work. One possible reason was due to the reaction $\mathrm{pH}$ value. The deposition process was conducted in acid solution in this work ( $\mathrm{pH} \sim 4)$, while in basic solution in the references ( $\mathrm{pH} \sim 9$ 11). The reaction rate was slower in this work than the one reported in the references.

\subsection{CNTs on GF surface}

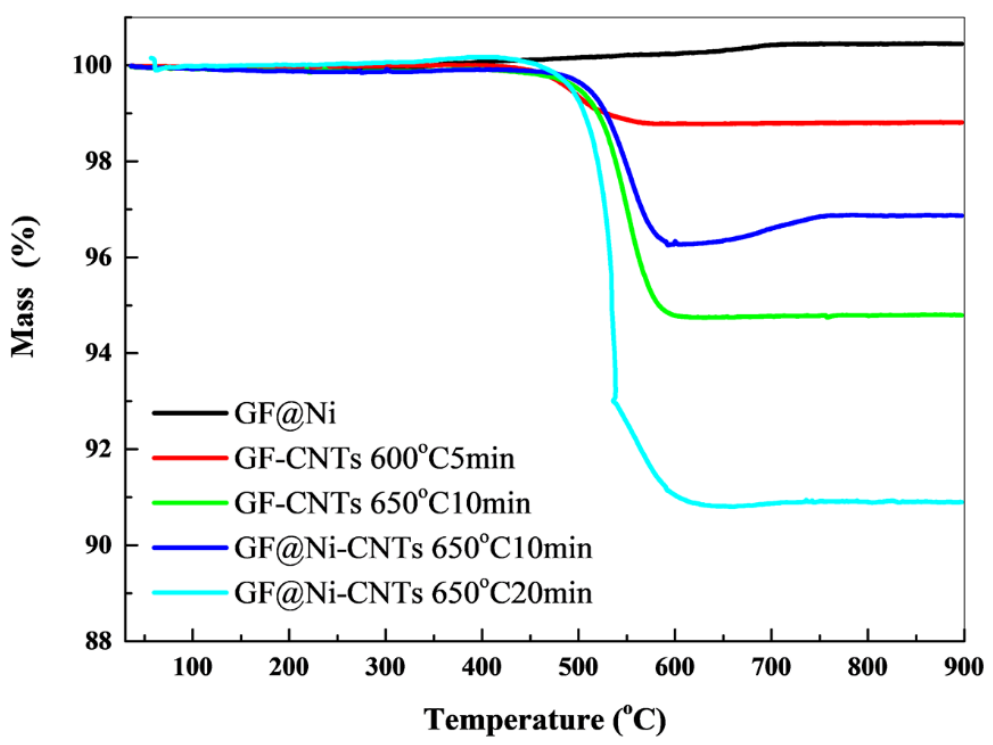

Figure 4 TGA curves of GF-CNTs, GF@Ni and GF@Ni-CNTs with varied CNTs mass fractions.

By using ferrocene as the catalyst precursor, the CNTs successfully grown on the GF and GF@Ni surface, as shown in Figure 1. After the growth of CNTs, the tissue color turned to black. In the CVD process, several parameters had critical influence on the CNT structures, such as the temperature, the synthesis time and the atmosphere, etc. In this work, the CVD process has been conducted at $600{ }^{\circ} \mathrm{C}$ and $650{ }^{\circ} \mathrm{C}$ with the synthesis time varied from 5 to 20 min. The TGA was conducted to evaluate the weight fraction of CNTs grown on the tissue. The results were showed in Figure 4. Even in an atmosphere of nitrogen and oxygen, the GF was thermally stable in the tested temperature range $\left(30-900{ }^{\circ} \mathrm{C}\right)$. The nickel layer was oxidized in 
the mixed atmosphere, which led to an addition of mass. The addition of mass was relatively low, less than $0.2 \mathrm{wt} \%$. Hence, the mass loss was mainly caused by the decomposition of CNTs, which decomposed largely at around $550{ }^{\circ} \mathrm{C}$. For the GF-CNTs, the mass loss was $1.2 \%$ for GF-CNTs growing at $600{ }^{\circ} \mathrm{C}$ for $5 \mathrm{~min}$, and $5.2 \%$ for GF-CNTs growing at $650{ }^{\circ} \mathrm{C}$ for $10 \mathrm{~min}$. For the GF@Ni-CNTs, the nickel layer had a negative influence on the growth of CNTs. By using the same CVD condition, the CNTs content was less than the GF-CNTs, e.g. 3.8\% for GF-CNTs growing at $650{ }^{\circ} \mathrm{C}$ for $10 \mathrm{~min}$. When prolonging the CVD time to $20 \mathrm{~min}$, the CNT content increased to $9.2 \%$. In the following description, the numbers were employed to represent the CVD condition, e.g. $5.2 \mathrm{wt} \%$ GF-CNTs represents the hybrids with $5.2 \mathrm{wt} \%$ of CNTs.

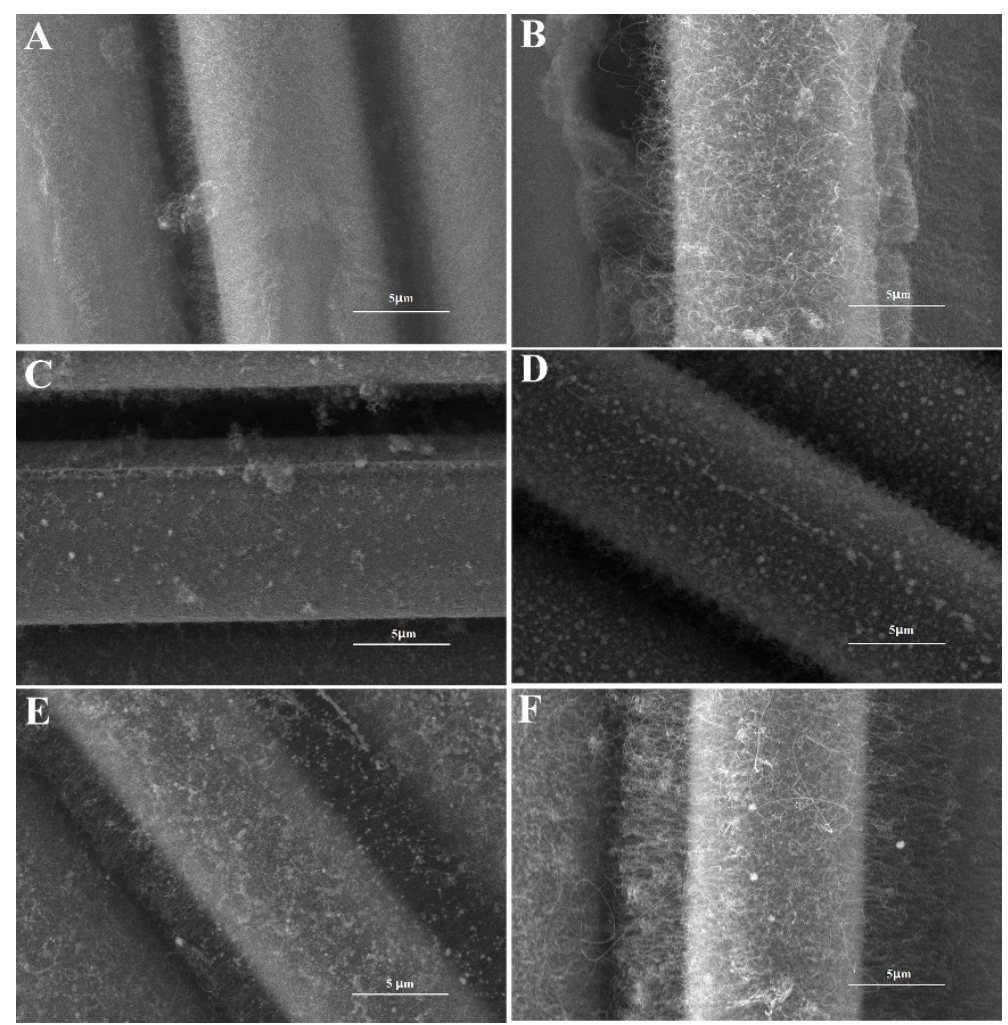

Figure 5 SEM images of GF-CNTs with synthesis time of (A) 5 min at $600{ }^{\circ} \mathrm{C}$ and (B) 10 $\min$ at $650^{\circ} \mathrm{C},(\mathrm{C}) \mathrm{GF} @ \mathrm{Ni}-\mathrm{CNT}$ s with synthesis time of $5 \mathrm{~min}$ at $600{ }^{\circ} \mathrm{C},(\mathrm{D}) \mathrm{GF} @ \mathrm{Ni}-\mathrm{CNTs}$ with synthesis time of $5 \mathrm{~min}$ at $650{ }^{\circ} \mathrm{C}$, (E) GF@Ni-CNTs with synthesis time of $10 \mathrm{~min}$ at $650{ }^{\circ} \mathrm{C}$ and (F) GF@Ni-CNTs with synthesis time of $20 \mathrm{~min}$ at $650^{\circ} \mathrm{C}$, respectively. 
Figure 5 showed the SEM images of the GF-CNTs and GF@Ni-CNTs with varied CNT mass fractions. The CNTs mass fraction on tissue can be modified by adjusting the synthesis conditions, such as temperature and synthesis time. In this work, two conditions have been used to make a comparison, $5 \mathrm{~min}$ at $600{ }^{\circ} \mathrm{C}$ (Figure 5A) and $10 \mathrm{~min}$ at $650{ }^{\circ} \mathrm{C}$ (Figure 5B) for GFCNTs, respectively. After reaction for $5 \mathrm{~min}$ at $600{ }^{\circ} \mathrm{C}$, the mass fraction was $1.2 \mathrm{wt} \%$, as measured by TGA. The CNTs were sparsely covered on GF surface. The length was about several hundred nanometers. When growing for $10 \mathrm{~min}$ at $650{ }^{\circ} \mathrm{C}$, the $\mathrm{GF}$ surface was completely covered by longer and denser CNTs (5.2 wt $\%)$. To investigate the influence of the temperature and synthesis time on the morphology of CNTs on the GF@Ni, the same reaction temperature, $600{ }^{\circ} \mathrm{C}$ and $650{ }^{\circ} \mathrm{C}$, were used to make a comparison with GF-CNTs. Figure 5C showed the morphology of GF@Ni-CNTs with reaction time of 5 min at $600{ }^{\circ} \mathrm{C}$. the CNT layer was about several hundred nanometers in a very sparse state. Some CNT clusters attached on the surface. The reaction time was also prolonged to $10 \mathrm{~min}$, but the CNTs were not homogeneous on the tissue. Figure 5D showed the morphology of GF@Ni-CNTs with reaction time of $5 \mathrm{~min}$ at $650{ }^{\circ} \mathrm{C}$. When we increased the temperature by $50{ }^{\circ} \mathrm{C}$, some bright particles appeared on the GF surface, which should be the Ni layer melted at high temperature and form the Ni clusters. The CNT layer was about several hundred nanometers in a relatively dense state. Figure 5E shows the morphology of GF@Ni-CNTs with reaction time of 10 min at $650{ }^{\circ} \mathrm{C}$. The CNT layer became thicker and much denser than the former one, which had a mass fraction of $3.8 \mathrm{wt} \%$. Some particles appeared at the end of CNTs, which might be the Ni particles supported by the CNTs. The reaction time has also been prolonged to $20 \mathrm{~min}$, longer and denser CNT layer has been obtained with a mass fraction of $9.2 \mathrm{wt} \%$, as shown in Figure 5F. Based on the SEM images, it can be concluded that the GF@Ni-CNTs were successfully prepared by CVD method. At $600^{\circ} \mathrm{C}$, the Ni layer can be maintained but the CNT layer was sparse and not homogeneous. At $650^{\circ} \mathrm{C}$, the Ni layer has been deformed into the separate clusters, but the CNT 
layer was homogeneous and in a relative dense state. The samples prepared at $650^{\circ} \mathrm{C}$ were chosen for the composite's fabrication.

\subsection{Composites preparation}
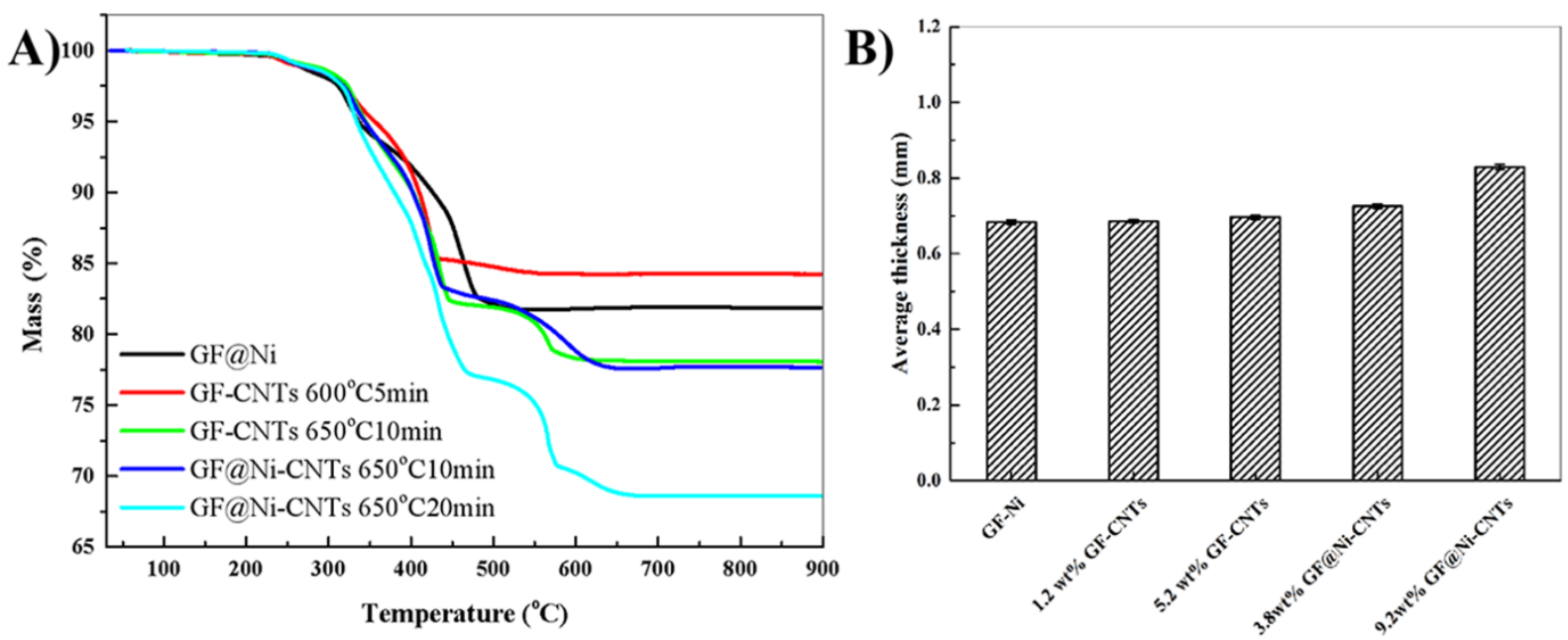

Figure 6 (A)TGA curves and (B) average thickness of GF-CNTs/epoxy and GF@NiCNTs/epoxy composites.

The sample thickness and the GF volume fraction have great influence on the EMI performance. To evaluate the GF volume fraction in the composites, the TGA has been conducted for all the composites. Figure 6A showed the TGA results of the GF@Ni/epoxy, GF-CNTs/epoxy and GF@Ni-CNTs/epoxy composites. A large mass loss was observed in the temperature range of $350-450{ }^{\circ} \mathrm{C}$. For the GF@Ni/epoxy composite, a mass loss of $18.2 \%$ happened. After growing CNT on the GF surface, there were two mass loss happened in different temperature. For the $1.2 \mathrm{wt} \% \mathrm{GF}-\mathrm{CNTs} / \mathrm{epoxy}$ composite $\left(600{ }^{\circ} \mathrm{C}\right.$ for $\left.5 \mathrm{~min}\right)$, a large mass loss was observed below the temperature of $450^{\circ} \mathrm{C}, 14.8 \%$, which was the decomposition of epoxy. The mass loss above $450^{\circ} \mathrm{C}, 1.0 \%$, mainly was attributed to the decomposition of CNTs. The decomposition of carbonized epoxy also contributed some mass loss. The same situation happened for other epoxy composites. For the $5.2 \mathrm{wt} \% \mathrm{GF}-\mathrm{CNTs} / \mathrm{epoxy}\left(650^{\circ} \mathrm{C}\right.$ for $\left.10 \mathrm{~min}\right)$, the values change to $17.2 \%$ for the decomposition of epoxy and $5.2 \%$ for the decomposition of CNTs and 
carbonized epoxy. For the 3.8wt $\%$ GF@Ni-CNTs/epoxy $\left(650{ }^{\circ} \mathrm{C}\right.$ for $\left.10 \mathrm{~min}\right)$, the two values were $18.0 \%$ and $3.9 \%$ for the decomposition of epoxy and CNTs (carbonized epoxy), respectively. For the $9.2 \mathrm{wt} \% \mathrm{GF} @ \mathrm{Ni}-\mathrm{CNTs} / \mathrm{epoxy}\left(650^{\circ} \mathrm{C}\right.$ for $\left.20 \mathrm{~min}\right)$, the two values were $23.2 \%$ and $8.2 \%$ for the decomposition of epoxy and CNTs (carbonized epoxy), respectively. As the CNTs became longer and denser, the CNT shell became thicker, which resulted in a thicker composite laminate. The average thickness of the composites varied from $0.7 \mathrm{~mm}$ for GF@Ni/epoxy to 0.8 mm for 9.2 wt\% GF@Ni-CNTs/epoxy, as shown in Figure 6B.

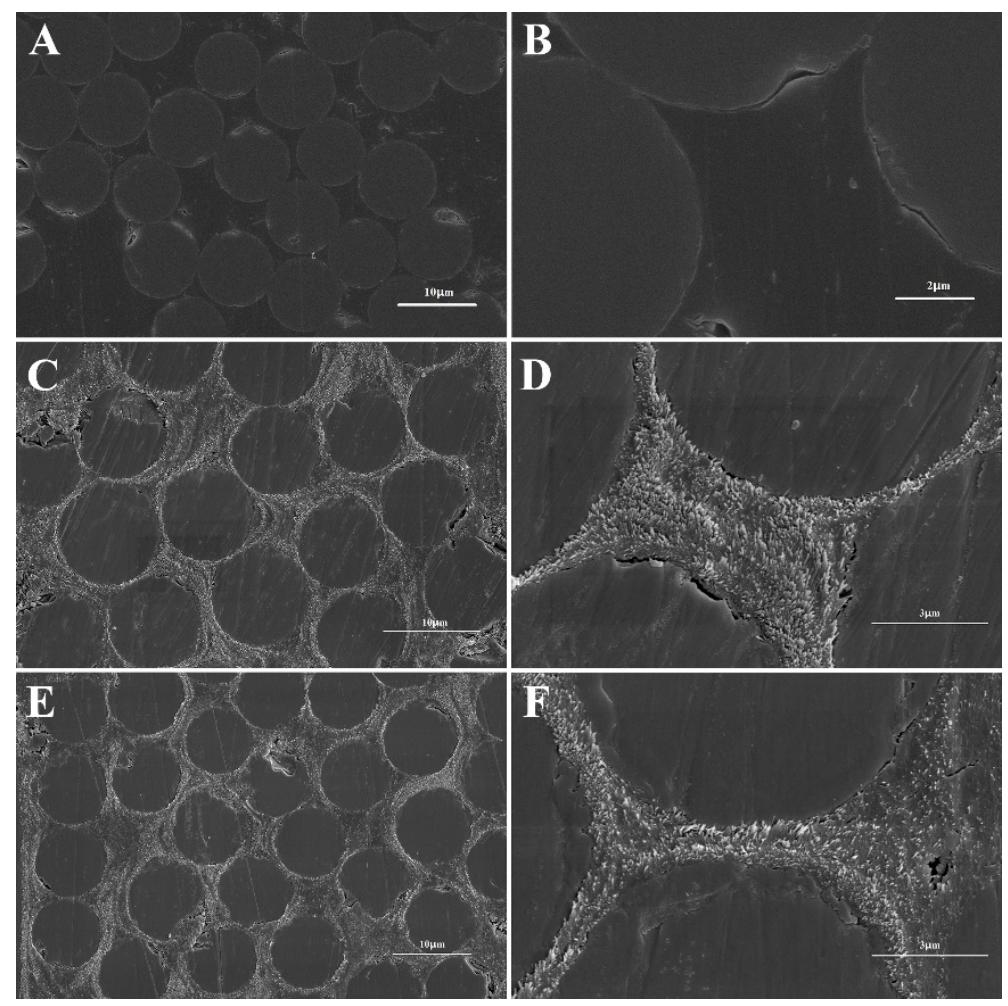

Figure 7 SEM images of cross-section of (A), (B) GF@Ni/epoxy, (C), (D) GF-CNTs/epoxy and (E), (F) GF@Ni-CNTs/epoxy composites.

Figure 7A and 7B showed the SEM images of cross-section of GF@Ni/epoxy composite. It was found that the diameter of glass fibers was around $9 \mu \mathrm{m}$ and the GFs were perfectly surrounded by the epoxy matrix without any evident air bubbles. The nickel layer was not obvious for the GF@Ni/epoxy composites. There was only a bright edge in the interface 
between GF and epoxy matrix. Figure 7C and 7D showed the cross-section of $5.2 \mathrm{wt} \%$ GFCNTs/epoxy. The circles were the cross-section of GF, the zone between the adjacent GFs were filled by the matrix and CNTs. It can be found that after the $0.7 \mathrm{MPa}$ hot press, the CNTs were pressed into a very dense state. The same morphology was observed in the 9.2 wt\% GF@NiCNTs/epoxy composite, the matrix was filled by the CNTs. The nickel layer was not obvious, as shown in Figure 7E and 7F.

\subsection{EMI performance}
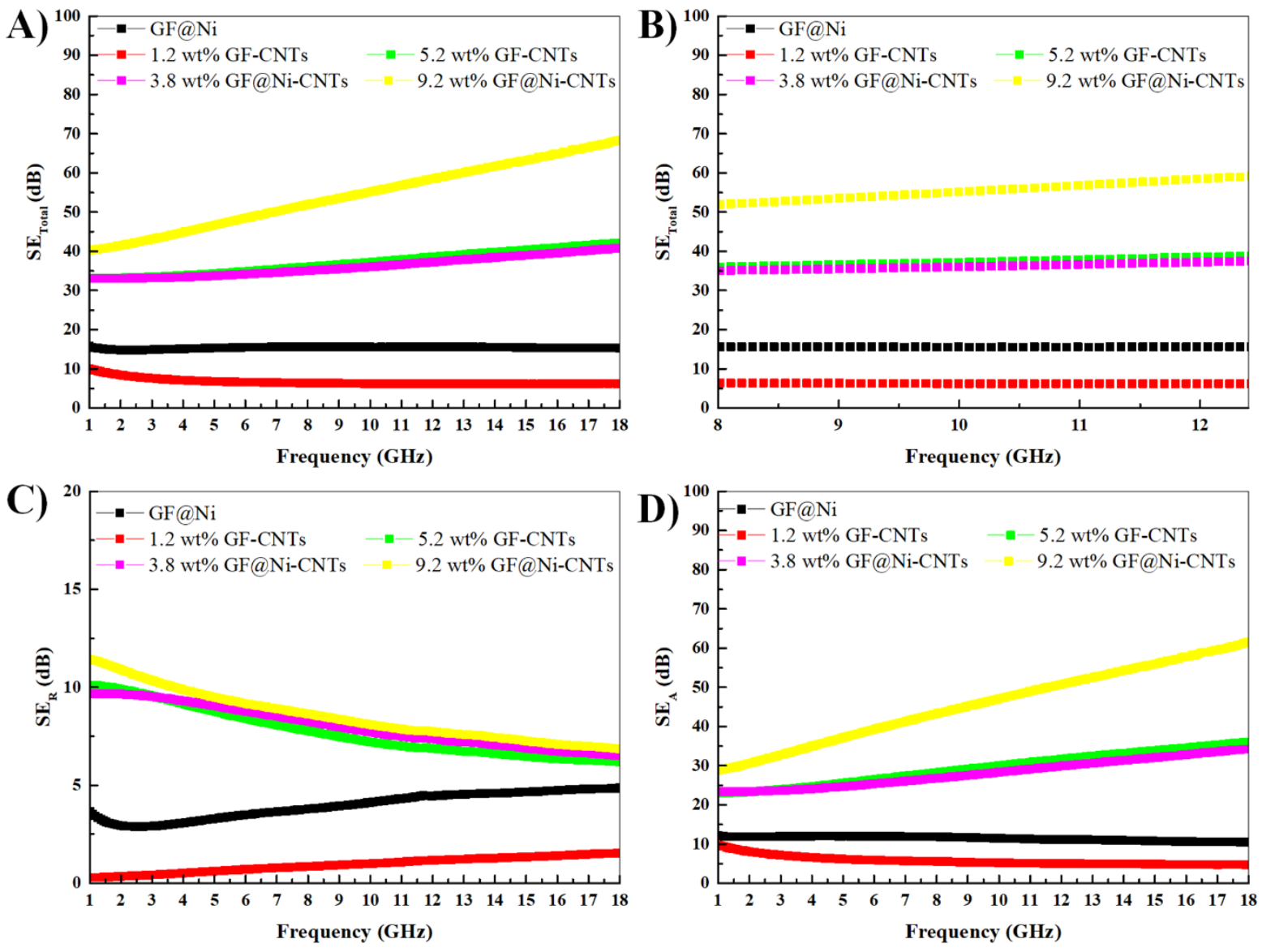

Figure $8 \mathrm{SE}$ total at (A) whole tested frequency ranging from 1 to $18 \mathrm{GHz}$ and (B) X band (8.212.4GHz), (C) SE of reflection part and (D) SE of absorption part of the composites.

Figure $8 \mathrm{~A}$ showed the $\mathrm{EMI} \mathrm{SE}_{\mathrm{T}}$ of the composites in the measured frequency region (1-18 $\mathrm{GHz}$ ). It slightly depended on frequency and gradually increased as the measurement frequency 
increases. The highest $\mathrm{SE}_{\mathrm{T}}$ was $70 \mathrm{~dB}$ at $18 \mathrm{GHz}$ for the $9.2 \mathrm{wt} \% \mathrm{GF} @$ Ni-CNTs/epoxy composites. As observed in the cross-section, the high CNTs formed a very dense state and surrounded the GF, which built a conductive network in the composite. The 3.8 wt $\%$ GF@NiCNTs/epoxy composite had the $\mathrm{SE}_{\mathrm{T}}$ of $40 \mathrm{~dB}$ at $18 \mathrm{GHz}$. It had almost the same EMI performance as the $5.2 \mathrm{wt} \%$ GF-CNTs/epoxy composite. It demonstrated the advantage of the nickel layer, which formed a completely conducting surface for the GF and offered a connection for the adjacent CNTs. It provided the same conductive network but with less CNTs. GF@Ni/epoxy had a $\mathrm{SE}_{\mathrm{T}}$ of $15 \mathrm{~dB}$, which was higher than that of the $1.2 \mathrm{wt} \% \mathrm{GF}-\mathrm{CNTs} / \mathrm{epoxy}$ composite. The low CNTs content has not formed a complete conductive network, which led to a low EMI performance, about $5 \mathrm{~dB}$ in the whole test frequency range. Figure 8B showed the EMI performance in the $\mathrm{X}$ band $(8.2-12.4 \mathrm{GHz})$. The $\mathrm{SE}_{\mathrm{T}}$ of $9.2 \mathrm{wt} \% \mathrm{GF} @ \mathrm{Ni}-\mathrm{CNTs} / \mathrm{epoxy}$ composite exceeded $50 \mathrm{~dB}$ in the whole tested frequency range. These values were above 35 dB for 3.8 wt\% GF@Ni-CNTs/epoxy and 5.2 wt\% GF-CNTs/epoxy composite. The water in the final composites was negligible, since the CNTs/fiber hybrid tissue was immersed by epoxy resin and layered up for the curing at the optimized conditions. Furthermore, the samples were measured in a constant environment. The matrix is a wave-transparency material. When the electromagnetic wave (EMW) propagates to the composite, the EMW can easily pass the airmatrix interface. The 1D vertical CNTs and the flower-like structure of the GF@Ni-CNTs can induce multiple reflections and scatterings, which makes EMW convert into thermal energy in a long propagation path. Meanwhile, the Ni-CNTs shell can form a three-dimensional conductive network, resulting in strong conduction loss. In addition, Ni coating and GF form a core-shell structure, which trapped and dissipated the EMW transmitted into the GF. Some similar studies were compared, and the results were shown in Table 1, and the nickel layer combined CNTs modified GF tissue showed a better EMI performance, and they can be a good candidate for the EMI application. 
Table 1 EMI SE of various modified GF reinforced polymer composites measured in GHz range.

\begin{tabular}{|c|c|c|c|c|c|c|}
\hline Matrix & Fillers & $\begin{array}{c}\text { Frequency range } \\
(\mathrm{GHz})\end{array}$ & $\begin{array}{c}\text { Best } \mathrm{SE}_{\mathrm{T}} \\
(\mathrm{dB})\end{array}$ & $\begin{array}{c}\text { Thickness } \\
\text { (mm) }\end{array}$ & $\begin{array}{c}\mathrm{SE}_{\mathrm{T}} / \text { Thickness } \\
(\mathrm{dB} / \mathrm{mm})\end{array}$ & References \\
\hline Epoxy & CNT+glass fiber & $0.3-1$ & 26 & 10 & 2.6 & [27] \\
\hline PC & FeCoNi coated glass fiber & $\mathrm{X}$ band & 37 & 0.5 & 74 & [24] \\
\hline PP & Short glass fiber coated by Ni & $\mathrm{X}$ band & 22.2 & 2 & 11.1 & {$[28]$} \\
\hline PP & Ni coated short glass fiber & $\mathrm{X}$ band & 44.5 & 2 & 22.2 & [29] \\
\hline Epoxy & CNT-glass fiber hybrids & $\begin{array}{l}1.7-2.8 \\
5.3-7.1\end{array}$ & $\begin{array}{c}0.8 \\
1\end{array}$ & 0.44 & $\begin{array}{l}1.8 \\
2.3\end{array}$ & [30] \\
\hline $\begin{array}{l}\text { Unsaturated } \\
\text { polyester }\end{array}$ & $\mathrm{CNT}+$ glass fiber $+\mathrm{CF}$ & $0.03-1.5$ & 75 & 1.18 & 63.5 & {$[31]$} \\
\hline Epoxy & $5.2 \mathrm{wt} \%$ GF-CNTs & $\mathrm{X}$ band & 35 & 0.7 & 50 & \multirow{2}{*}{ This work } \\
\hline Epoxy & 9.2 wt\% GF@Ni-CNTs & $\mathrm{X}$ band & 51 & 0.83 & 61.4 & \\
\hline
\end{tabular}

Glass fiber is a kind of insulating materials. It is highly desired to improve its electrical conductivity in certain application such as EMI shielding. To this end, in-situ growing CNTs on its surface is one of the most effective ways. However, as-grown CNTs are vertically aligned on the surface of the insulating glass fiber. Thus, the electrical conductivity of the composites depends greatly on conductive network formed by intercontact carbon nanotubes. In such application, the advantages of carbon nanotubes are numerous: lightweight, high conductivity, multifunctionality, and high mechanical performance, compared to other counterparts such as metals. Nevertheless, the high contact resistance greatly limits the conductivity of the composites. When a thin layer of nickel is deposited on the surface of glass fibers, it could improve the electrical conductivity of nanotube networks and thus this of the composite, at the same time maintain other advantages of this hierarchical multifunctional reinforcement of nanotubes/fibers. For this consideration, this work was conducted in order to experimentally demonstrate the impact of nickel deposition on the EMI performance of such hybrid composites. The nickel was also chosen as the model materials since it is widely used to coat glass fibers, and it is also one kind of the widely used catalytic materials for carbon nanotube growth. At the current stage, both the CVD syntheses and the composites are realized at quite small scale, thus 
it is quite difficult to give an accurate estimation of the cost. In an economic point of view, it might be replaced late by other relatively cheap metals.

\section{Conclusion}

In summary, in-situ growth of CNTs on nickel coated glass fiber tissue was achieved by a onestep CVD, and the grafted CNTs homogeneously and perpendicularly aligned on the surface of each fiber, forming a "core-shell" structure. Then, three types of composites were prepared, including GF@Ni, GF-CNTs and GF@Ni-CNTs. The EMI shielding effectiveness of composites was examined as a function of CNTs content. The best EMI performance was obtained by using 9.2 wt\% GF@Ni-CNTs as fillers, which was above $35 \mathrm{~dB}$ in the range of 1$18 \mathrm{GHz}$, and above $50 \mathrm{~dB}$ in the $\mathrm{X}$ band. By incorporating the nickel layer on the GF surface, the same EMI performance can be achieved with lower CNTs content. The 3.8wt\% GF@NiCNTs/epoxy and the $5.2 \mathrm{wt} \%$ GF-CNTs/epoxy composites have the SE value of $35 \mathrm{~dB}$ in the X band. Thus, the GF@Ni with aligned CNTs endows conventional GFRPs with good EMI performance, which allows extending GFRP applications in the fields of automobile, aeronautics and astronautics, etc.

\section{Acknowledgement}

This work has benefited from the financial support of the LabEx LaSIPS, France (ANR-10LABX-0032-LaSIPS) managed by the French National Research Agency under the “Investissements d'avenir” program (ANR-11-IDEX-0003).

\section{Conflict of interest}

The authors declare no conflict of interest.

\section{Data availability}


All data generated or analyzed during this study are included in this published article.

\section{References}

[1] F. Shahzad, M. Alhabeb, C.B. Hatter, B. Anasori, S. Man Hong, C.M. Koo, Y. Gogotsi, Electromagnetic interference shielding with 2D transition metal carbides (MXenes), Science, 353 (2016) 1137.

[2] P.J. Bora, K.J. Vinoy, P.C. Ramamurthy, Kishore, G. Madras, Lightweight polyaniline-cobalt coated fly ash cenosphere composite film for electromagnetic interference shielding, Electronic Materials Letters, 12 (2016) 603-609.

[3] D.D.L. Chung, Electrical applications of carbon materials, Journal of Materials Science, 39 (2004) 2645-2661.

[4] S. Geetha, K.K. Satheesh Kumar, C.R.K. Rao, M. Vijayan, D.C. Trivedi, EMI shielding: Methods and materials-A review, Journal of Applied Polymer Science, 112 (2009) 2073-2086.

[5] A. Ameli, P.U. Jung, C.B. Park, Electrical properties and electromagnetic interference shielding effectiveness of polypropylene/carbon fiber composite foams, Carbon, 60 (2013) 379-391.

[6] L.-Q. Zhang, S.-G. Yang, L. Li, B. Yang, H.-D. Huang, D.-X. Yan, G.-J. Zhong, L. Xu, Z.-M. Li, Ultralight Cellulose Porous Composites with Manipulated Porous Structure and Carbon Nanotube Distribution for Promising Electromagnetic Interference Shielding, ACS Applied Materials \& Interfaces, 10 (2018) 40156-40167.

[7] H.-B. Zhang, Q. Yan, W.-G. Zheng, Z. He, Z.-Z. Yu, Tough Graphene-Polymer Microcellular Foams for Electromagnetic Interference Shielding, ACS Applied Materials \& Interfaces, 3 (2011) 918924.

[8] A. Ameli, M. Nofar, S. Wang, C.B. Park, Lightweight Polypropylene/Stainless-Steel Fiber Composite Foams with Low Percolation for Efficient Electromagnetic Interference Shielding, ACS Applied Materials \& Interfaces, 6 (2014) 11091-11100.

[9] X. Luo, D.D.L. Chung, Electromagnetic interference shielding using continuous carbon-fiber carbon-matrix and polymer-matrix composites, Composites Part B: Engineering, 30 (1999) 227-231.

[10] K.H. Wong, S.J. Pickering, C.D. Rudd, Recycled carbon fibre reinforced polymer composite for electromagnetic interference shielding, Composites Part A: Applied Science and Manufacturing, 41 (2010) 693-702.

[11] T. Sathishkumar, S. Satheeshkumar, J. Naveen, Glass fiber-reinforced polymer composites - a review, Journal of Rnforced Plastics \& Composites, 33 (2014) 1258-1275.

[12] A.T. DiBenedetto, Tailoring of interfaces in glass fiber reinforced polymer composites: a review, Materials Science and Engineering: A, 302 (2001) 74-82.

[13] Y. Tai, H. Chen, C. Xu, Y. Liu, Conductive glass fabrics@nickel composites prepared by a facile electroless deposition method, Materials Letters, 171 (2016) 158-161.

[14] M. Angappan, P.J. Bora, K.J. Vinoy, P.C. Ramamurthy, K. Vijayaraju, Tailorable electromagnetic interference shielding using nickel coated glass fabric-epoxy composite with excellent mechanical property, Composites Communications, 10 (2018) 110-115.

[15] A. Markov, B. Fiedler, K. Schulte, Electrical conductivity of carbon black/fibres filled glass-fibrereinforced thermoplastic composites, Composites Part A: Applied Science and Manufacturing, 37 (2006) 1390-1395.

[16] A. Warrier, A. Godara, O. Rochez, L. Mezzo, F. Luizi, L. Gorbatikh, S.V. Lomov, A.W. VanVuure, I. Verpoest, The effect of adding carbon nanotubes to glass/epoxy composites in the fibre sizing and/or the matrix, Composites Part A: Applied Science and Manufacturing, 41 (2010) 532-538.

[17] L. Liao, X. Wang, P. Fang, K.M. Liew, C. Pan, Interface Enhancement of Glass Fiber Reinforced Vinyl Ester Composites with Flame-Synthesized Carbon Nanotubes and Its Enhancing Mechanism, ACS Applied Materials \& Interfaces, 3 (2011) 534-538.

[18] J.A. Kim, D.G. Seong, T.J. Kang, J.R. Youn, Effects of surface modification on rheological and mechanical properties of CNT/epoxy composites, Carbon, 44 (2006) 1898-1905.

[19] A.I. Isayev, R. Kumar, T.M. Lewis, Ultrasound assisted twin screw extrusion of polymernanocomposites containing carbon nanotubes, Polymer, 50 (2009) 250-260. 
[20] Z. Špitalský, C.A. Krontiras, S.N. Georga, C. Galiotis, Effect of oxidation treatment of multiwalled carbon nanotubes on the mechanical and electrical properties of their epoxy composites, Composites Part A: Applied Science and Manufacturing, 40 (2009) 778-783.

[21] H. Qian, A. Bismarck, E.S. Greenhalgh, G. Kalinka, M.S.P. Shaffer, Hierarchical Composites Reinforced with Carbon Nanotube Grafted Fibers: The Potential Assessed at the Single Fiber Level, Chemistry of Materials, 20 (2008) 1862-1869.

[22] K.J. Kim, J. Kim, W.-R. Yu, J.H. Youk, J. Lee, Improved tensile strength of carbon fibers undergoing catalytic growth of carbon nanotubes on their surface, Carbon, 54 (2013) 258-267.

[23] D. He, B. Fan, H. Zhao, X. Lu, M. Yang, Y. Liu, J. Bai, Design of Electrically Conductive Structural Composites by Modulating Aligned CVD-Grown Carbon Nanotube Length on Glass Fibers, ACS Applied Materials \& Interfaces, 9 (2017) 2948-2958.

[24] J. Lee, B.M. Jung, S.B. Lee, S.K. Lee, K.H. Kim, FeCoNi coated glass fibers in composite sheets for electromagnetic absorption and shielding behaviors, Applied Surface Science, 415 (2017) 99-103.

[25] T.K. Gupta, B.P. Singh, S.R. Dhakate, V.N. Singh, R.B. Mathur, Improved nanoindentation and microwave shielding properties of modified MWCNT reinforced polyurethane composites, Journal of Materials Chemistry A, 1 (2013) 9138-9149.

[26] B.J. Kim, W.K. Choi, H.S. Song, J.K. Park, J.Y. Lee, S.J. Park, Preparation and Characterization of Highly Conductive Nickel-coated Glass Fibers, Carbon Letters, 9 (2008).

[27] K.-Y. Park, S.-E. Lee, C.-G. Kim, J.-H. Han, Application of MWNT-added glass fabric/epoxy composites to electromagnetic wave shielding enclosures, Composite Structures, 81 (2007) 401-406.

[28] H. Duan, M. Zhao, Y. Yang, G. Zhao, Y. Liu, Flexible and conductive PP/EPDM/Ni coated glass fiber composite for efficient electromagnetic interference shielding, Journal of Materials Science: Materials in Electronics, 29 (2018) 10329-10336.

[29] H. Duan, J. Yang, Y. Yang, G. Zhao, Y. Liu, TiO2 hybrid polypropylene/nickel coated glass fiber conductive composites for highly efficient electromagnetic interference shielding, Journal of Materials Science: Materials in Electronics, 28 (2017) 5725-5732.

[30] A.Y. Boroujeni, M. Tehrani, M. Manteghi, Z. Zhou, M. Al-Haik, Electromagnetic Shielding Effectiveness of a Hybrid Carbon Nanotube/Glass Fiber Reinforced Polymer Composite, Journal of Engineering Materials \& Technology, 138 (2016) 041001.041001-041001.041006.

[31] J.R.N. Gnidakouong, M. Kim, H.W. Park, Y.-B. Park, H.S. Jeong, Y.B. Jung, S.K. Ahn, K. Han, J.-M. Park, Electromagnetic interference shielding of composites consisting of a polyester matrix and carbon nanotube-coated fiber reinforcement, Composites Part A: Applied Science and Manufacturing, 50 (2013) 73-80. 